\title{
Ontogeny of epididymal sperm reserves during the reproductive lifespan of rats after previous sexual experiences
}

\author{
G. T. Taylor*†, J. Weiss $\ddagger$ and T. Frechmann§ \\ *Department of Biology, The University of Tokyo, Tokyo 153, Japan; $\ddagger$ Institute fur \\ Versuchstierkunde, Universitat Heidelberg, F.R.G.; and §Department of Psychology, University of \\ Missouri-St Louis, St Louis, MO 63121, U.S.A.
}

\begin{abstract}
Summary. Epididymal sperm quantity and quality were examined throughout the reproductive lifespan of sexually experienced and inexperienced rats. Males were housed with gonadally intact or ovariectomized females for 2 weeks to 1 year, and epididymides were analysed 1 week to 9 months after the females were removed. Results for the virgin males suggest a peak in sperm numbers at 6 months of age followed by a gradual decline and then notable decrements in sperm numbers and motility by 24 months of age. The same general pattern emerged for sexually experienced males, with two exceptions. There was a chronic increase of sperm numbers relative to those of virgin males at every age examined, and the decline in spermatozoa with ageing was slowed by previous sexual contact. The implications of these data for the ontogeny of fertility are not readily apparent because the epididymis remained reproductively functional throughout the lifespan. We do, however, suggest that epididymides are sensitive to experiential and hormonal changes during adulthood and, most important, the effects of these changes are maintained chronically and into old age.
\end{abstract}

\section{Introduction}

Changes in fecundity with ageing have considerable theoretical and applied importance. Comparisons of young and old male conspecifics indicate that, despite individual variability, there are marked decremental changes with age in various subsystems contributing to reproduction (Bishop, 1970; Bethea \& Walker, 1979). Spermatogenesis and epididymal sperm reserves are one important example, the aged male has fewer spermatozoa than does the younger animal (Johnson, Petty, Porter \& Neaves, 1984). There are relatively few studies of the ontogeny of the subsystems throughout the reproductive lifespan, and generalizations are more tenuous. The suggestion, nonetheless, is that functional declines begin with middle age and end with reproductive senescence in the old male (Talbert, 1977; Bronson \& Desjardins, 1982). Reductions in concentrations of circulating and intratesticular testosterone are an example of such an ageing process (Kinoshita, Higashi, Winters, Oshima \& Troen, 1985).

Gonadotrophic and testicular hormones are critical for maintenance of much of the reproductive system, including normal spermatogenesis and epididymal functioning (Brooks, 1981). And exogenous hormone treatments to older males have restored youthful functioning, at least temporarily, to some subsystems (Bolla, 1982). An hormonal model of reproductive senescence based on declining circulating testosterone is probably too simplistic (Chambers \& Phoenix,

† Present address: Department of Psychology, University of Missouri-St Louis, St Louis, MO 63121-4499, U.S.A. 
1984). Hormone release patterns (Steiner, Bremner, Clifton \& Dorsa, 1984) and hypothalamushypophysis interactions (Riegle, 1982) may prove more important.

Copulation in young adult males induces changes in hormone release patterns and central mechanism activity (Desjardins, 1981) with acute and chronic consequences for their reproductive systems (Taylor, Weiss \& Komitowski, 1983). There are acute (Weizenbaum, Matthews, Whitehouse \& Adler, 1981; Taylor, Weiss, Frechmann \& Haller, 1985a), as well as the suggestion of chronic (Vitale-Calpe \& Burgos, 1970), increases in sperm reserves after copulation. The present study with ageing male rats was suggested by those data. The hypothesis tested was that extensive sexual experience would induce chronic increments in epididymal sperm reserves throughout the reproductive lifespan and into old age.

\section{Materials and Methods}

The rats were of the Wistar strain, and there were 20 males at the ages of 3,6, 9, 12 or 24 months at the time of epididymal analyses. Half of the animals in each age category were sexually experienced and the others remained virgins. Copulatory experience was obtained by cohabitation with 2 females beginning at about 90 days of age. Females were changed at about 1-month intervals to ensure that the males received varied experience with females; pregnancies were used to confirm the multiple sexual experiences. At the same time, the sexually inexperienced males were housed with ovariectomized females and, otherwise, treated identically to the experienced males.

Cages were either opaque plastic, $39 \times 21.5 \times 15 \mathrm{~cm}$, or metal, $56 \times 27 \times 21 \mathrm{~cm}$. Water and

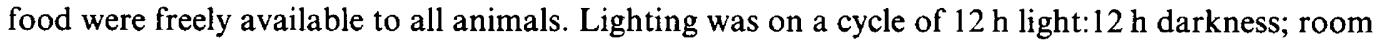
temperature $\left(22 \pm 2^{\circ} \mathrm{C}\right)$ and relative humidity $(55 \pm 5 \%)$ were controlled automatically.

Because we were interested in long-term epididymal changes, females were removed from the cages of the males of both conditions before analyses. For the 6-, 9- and 12-month-old males this was 1 month. By necessity, the period was shorter for the 3-month-old males. They were placed with females on Day 65 of age and females were removed 10 days before testing. The period between removal of females and testing for the 24 -month-old males was 9 months.

Rats were killed with an overdose of pentobarbitone sodium and epididymides were removed and weighed. The organs were individually prepared for analyses of numbers and motility using methods described earlier (Taylor et al., 1985a). Essentially, two samples of spermatozoa from each animal were counted from 7 chambers of a haemocytometer. The extreme scores were eliminated and a mean value was obtained from the remaining 5 counts. Motility was defined in terms of forward movement (Lopata, Patullo, Chang \& James, 1976).

\section{Results}

The measures of epididymal contents were numbers and motility of spermatozoa. Those data, as well as wet weights of epididymides, were recorded for each of the 10 animals from each experiential condition from each of the 5 age groups. The results are reported as means \pm s.e.m. in Table 1 . The data were statistically analysed with a series of $2 \times 5$ factorial analyses of variance, with experience and age as the main factors. Tukey's Honestly Significant Difference tests (HSD, $P<0.01$ ) were used for post-hoc comparisons of group means.

There was a statistically significant interaction between the main effects in relation to sperm numbers per $\mathrm{g}$ epididymal tissue $(F(4,90)=6.04, P<0.01)$. Further analyses of simple main effects were performed on each of the two factors. Results for the age factor revealed that the sexually experienced males had greater sperm numbers than did virgin males of comparable age at each stage of ontogeny $(F(1,90)=$ range $28 \cdot 76-117 \cdot 48, P<0.01)$. In addition, the differences amongst experienced and inexperienced sets of animals proved statistically significant $(F(4,90)=$ 
Table 1. Analyses of epididymides from sexually experienced (SE) and inexperienced (SI) rats from 3 to 24 months of age

\begin{tabular}{lccccc}
\hline & \multicolumn{5}{c}{ Age (months) } \\
\cline { 2 - 6 } & 3 & 6 & 9 & 12 & 24 \\
\hline $\begin{array}{l}\text { Sperm numbers }\left(\times 10^{-6}\right) / \mathrm{g} \\
\quad \text { tissue }\end{array}$ & $329 \pm 6 \cdot 61^{\mathrm{a}}$ & $373 \pm 9 \cdot 58^{\mathrm{b}}$ & $310 \pm 6 \cdot 98^{\mathrm{a}}$ & $287 \pm 9 \cdot 09^{\mathrm{a}}$ & $226 \pm 10 \cdot 30^{\mathrm{c}}$ \\
$\quad$ SI & $329 \pm 10 \cdot 55^{\mathrm{d}}$ & $458 \pm 9 \cdot 43^{\mathrm{c}}$ & $465 \pm 8 \cdot 22^{\mathrm{c}}$ & $432 \pm 8 \cdot 22^{\mathrm{c}}$ & $347 \pm 14 \cdot 14^{\mathrm{f}}$ \\
$\quad$ SE & & & & & \\
Sperm motility (\%) & $58 \pm 1 \cdot 78^{\mathrm{a}}$ & $59 \pm 1 \cdot 49^{\mathrm{a}}$ & $57 \pm 2 \cdot 02^{\mathrm{a}}$ & $60 \pm 2 \cdot 03^{\mathrm{a}}$ & $37 \pm 1 \cdot 37^{\mathrm{b}}$ \\
$\quad$ SI & $70 \pm 1 \cdot 55^{\mathrm{c}}$ & $66 \pm 1 \cdot 28^{\mathrm{a}}$ & $66 \pm 2 \cdot 22^{\mathrm{c}}$ & $63 \pm 3 \cdot 03^{\mathrm{a}}$ & $44 \pm 1 \cdot 90^{\mathrm{b}}$ \\
$\quad$ SE & & & & & \\
Weight of epididymides $(\mathrm{mg})$ & $787 \pm 22^{\mathrm{a}}$ & $1.056 \pm 33^{\mathrm{b}}$ & $1 \cdot 108 \pm 29^{\mathrm{b}}$ & $1 \cdot 025 \pm 18^{\mathrm{b}}$ & $987 \pm 33^{\mathrm{b}}$ \\
$\quad$ SI & $884 \pm 26^{\mathrm{a}}$ & $1 \cdot 092 \pm 34^{\mathrm{b}}$ & $1 \cdot 112 \pm 32^{\mathrm{b}}$ & $1 \cdot 077 \pm 30^{\mathrm{b}}$ & $1 \cdot 131 \pm 31^{\mathrm{c}}$ \\
$\quad$ SE & &
\end{tabular}

Values are mean \pm s.e.m., for all the males in each group.

Values with different superscript letters are significantly different (Tukey's HSD, $P<0.01$ ).

22.47 and 29.24 , respectively, $P<0.01$ ). Tukey's HSD test revealed that the ordering of the age groups from greatest to least sperm numbers were, for experienced males, $6=9=12>3>24$ months and, for inexperienced males, $6>3=9=12>24$ months.

Analyses of the percentages of motile spermatozoa indicated significance for both experience $(F(1,90)=34.90, \quad P<0.01)$ and age $(F(4,90)=47.40, \quad P<0.01)$, but not the interaction $(F(4,90)=1 \cdot 01)$. Tukey's test revealed that only at 3 and 9 months of age was there increased sperm motility with previous sexual experiences. The only age groups that differed within both experiential conditions were the old rats: sperm motility was reduced in both sets of 24-month-old males. Finally, statistically significant values were obtained for both experience and age main effects $(F(1,90)=10.55$ and $F(4,90)=25.74, P<0.01)$ for the epididymal weights. Tukey's test demonstrated that the 3-month-old rats of both experiential conditions had lighter epididymides than did the older males and only the sexually experienced 24-month-old males had heavier organs than did their respective inexperienced age group.

\section{Discussion}

The purpose of the experiment was to examine the ontogeny of epididymal sperm reserves throughout the reproductive lifespan of the rat, as well as the interaction of age with prior sexual experiences. The findings suggest that both age and experience exert a profound influence upon the epididymal milieu. Of our measures of epididymal function, sperm numbers were highly sensitive to the experimental manipulation, but sperm motility and wet weights of epididymides were somewhat less sensitive.

The ontogenetic pattern for sexually inexperienced males was a peak in sperm numbers at about 6 months of age with a gradual decline until 'middle age' at 12 months, followed by a significant decrease in the aged 24-month-old rats. This pattern may be characteristic of the adult ontogeny of many of the subsystems contributing to reproduction (Grota, 1971; Bronson \& Desjardins, 1977). There was a similar peak response in the ontogeny of sperm counts in the sexually experienced males, also with a substantial reduction at old age (Bronson \& Desjardins, 1982). The decline, however, was slower in the sexually experienced than the sexually inexperienced males. Indeed, previous 
sexual contact elevated reserves above the sperm numbers of virgin males at every age throughout the reproductive lifespan and including old age (Breakey, 1963). These were chronic changes in sperm counts since the analyses were made long after males and females were separated.

We were interested in long-lasting modifications after sexual interactions for three reasons. First, physiological recovery in the male may mask changes when epididymides are examined soon after copulation (Dewsbury, 1982; Taylor et al., 1985a). Second, we had found (unpublished data) that various subsystems were chronically modified in old sexually experienced males. The present findings confirm those data. The sexually experienced males, albeit with extensive previous sexual activity (Drori \& Folman, 1964), maintained a sperm advantage over sexually inexperienced males for up to 9 months, or a remarkable $40 \%$ of the lifespan of a rat. Third, we are intrigued by chronic changes in reproductive morphology and functioning after exposures to acute pulses of endogenous (Taylor et al., 1983) and exogenous (Taylor, Weiss \& Haller, 1985b) hormones, pulses such as those that accompany copulation (Kamel \& Frankel, 1978). The present findings provide additional evidence that there is a chronic response by the epididymides to acute changes in endocrinology and experience.

The percentage of motile spermatozoa was constant during ontogeny, with the notable exception of a very sharp decline at 24 months of age. Previous copulatory experiences had modest effects with higher motility in sexually experienced males only at 3 and 9 months of age. Spermatogenesis in immediately post-pubertal males may be particularly sensitive to hormonal and experiential manipulations (Setchell, Duggan \& Evans, 1973; Taylor et al., 1983) because the reproductive system is not fully mature until 4-5 months of age (Robb, Amann \& Killian, 1978). There was an indication of increased sperm motility in aged sexually experienced males, but the differences with virgin males failed to achieve statistical significance.

Sperm quantity and quality clearly were reduced in old rats, but the consequences for fecundity are equivocal (Saksena, Lau \& Chang, 1979; Robaire, Smith \& Hales, 1984). Perhaps the most important conclusion from the present data is that different experiences during adulthood can modify epididymal contents. Increased sperm reserves in sexually experienced animals may be due to elevated spermatogenesis, but we believe that the sperm counts are higher because of inhibition of sperm elimination from the epididymides (Taylor et al., 1985a).

The research was supported, in part, by grants from the University of Missouri (U.S.A.) and the Alexander Von Humboldt Foundation (F.R.G.). We thank Masashi Daumae, University of Tokyo, for assistance in preparing the manuscript.

\section{References}

Bethea, C.L. \& Walker, R.F. (1979) Age-related changes in reproductive hormones and in Leydig cell response in the male Fischer 344 rat. J. Gerontol. 32, 21-27.

Bishop, M.W.H. (1970) Ageing and reproduction in the male. J. Reprod. Fert., Suppl. 12, 65-87.

Bolla, R. (1982) Hormonal regulation of molecular events during aging. Life Sci. 331, 615-623.

Breakey, D.R. (1963) The breeding season and age structure of feral house mouse populations near San Francisco Bay, California. J. Mammal. 44, 153-168.

Bronson, F.H. \& Desjardins, C. (1977) Reproductive failure in aged $\mathrm{CBF}_{1}$ male mice: interrelationships between pituitary gonadotropic hormones, testicular function and mating success. Endocrinology 101, 939-945.

Bronson, F.H. \& Desjardins, C. (1982) Relative effects of exercise, diet and female stimulation on sexual aging of male mice. J. Gerontol. 37, 555-559.
Brooks, D.E. (1981) Metabolic activity in the epididymis and its regulation by androgens. Physiol. Rev. 61, 515-555.

Chambers, K.C. \& Phoenix, C.H. (1984) Testosterone and the decline of sexual behavior in aging male rats. Behav. Neural Biol. 40, 87-97.

Desjardins, C. (1981) Endocrine signaling and male reproduction. Biol. Reprod. 24, 1-21.

Dewsbury, D.A. (1982) Ejaculate cost and mate choice. Am. Nat. 111, 606-610.

Drori, D. \& Folman, Y. (1964) Effects of cohabitation on the reproductive system, kidneys and body composition of male rats. J. Reprod. Fert. 8, 351-359.

Grota, L.J. (1971) Effects of age and experience on plasma testosterone. Neuroendocrinology 8, 136-143.

Johnson, L., Petty, C.S., Porter, J.C. \& Neaves, W.B. (1984) Germ cell degeneration during postprophase of meiosis and serum concentrations of gonado- 
tropins in young adult and older adult men. Biol. Reprod. 31, 779-784.

Kamel, F. \& Frankel, A.I. (1978) Hormone release during mating in the male rat: time course, relation to sexual behavior, and interaction with handling procedures. Endocrinology 103, 2172-2179.

Kinoshita, Y., Higashi, Y., Winters, S.J., Oshima, H. \& Troen, P. (1985) An analysis of age-related decline in testicular steroidogenesis in the rat. Biol. Reprod. 32, 309-314.

Lopata, A., Patullo, M.J., Chang, A. \& James, B. (1976) A method for collecting motile spermatozoa from human semen. Fert. Steril. 27, 677-682.

Riegle, G.D. (1982) Endocrine regulation of the testis in the aged male. In Endocrine and Neuroendocrine Mechanisms of Aging, pp. 105-122. Eds R. C. Adelman \& G. S. Roth. CRC, Boca Raton.

Robaire, B., Smith, S. \& Hales, B.F. (1984) Suppression of spermatogenesis by testosterone in adult male rats: effect on fertility, pregnancy outcome and progeny. Biol. Reprod. 31, 221-230.

Robb, G.W., Amann, R.P. \& Killian, G.J. (1978) Daily sperm production and epididymal sperm reserves of pubertal and adult rats. J. Reprod. Fert. 54, 103-107.

Saksena, S.K., Lau, I.F. \& Chang, M.C. (1979) Age dependent changes in the sperm population and fertility in the male rat. Exp. Aging Res. 5, 373-381.

Setchell, B.P., Duggan, M.C. \& Evans, R.W. (1973) The effect of gonadotrophins on fluid secretion and sperm production by the rat and hamster testis. $J$. Endocr. 56, 27-36.
Steiner, R.A., Bremner, W.J., Clifton, D.K. \& Dorsa, D.M. (1984) Reduced pulsatile luteinizing hormone and testosterone secretion with aging in the male rat. Biol. Reprod. 31, 251-258.

Talbert, G.B. (1977) Aging in the reproductive system. In Handbook of the Biology of Ageing, pp. 318-356. Eds C. E. Finch \& L. Hayflick. Van Nostrand, New York.

Taylor, G.T., Weiss, J. \& Komitowski, D. (1983) Reproductive physiology and penile papillae morphology of rats after sexual experience. J. Endocr. 98, 155-163.

Taylor, G.T., Weiss, J., Frechmann, T. \& Haller, J. (1985a) Copulation induces an acute increase in epididymal sperm numbers in rats. $J$. Reprod. Fert. 73, 323-327.

Taylor, G.T., Weiss, J. \& Haller, J. (1985b) Chronic changes in male rats' hormone-sensitive systems after suprathreshold pulses of testosterone. Anat. Rec. 211, 304-310.

Vitale-Calpe, R. \& Burgos, M.H. (1970) The mechanism of spermiation in the hamster. II. The ultrastructural effects of coitus and LH administration. J. Ultrastruct. Res. 31, 394-406.

Weizenbaum, F.A., Matthews, M., Whitehouse, J. \& Adler, N. (1981) Depressant effects of sexual rest on reproductive behavior and physiology in male rats. Biol. Reprod. 25, 744-751.

Received 19 September 1986 